\title{
Possible Treatment of Breast Cancer by Activation of Pineal as a Psycho-Neuro-Endocrine Transducer and a Circadian Clock Gene Modifier through Behavioral Stimuli and Light Therapy
}

\author{
Samina Malik* \\ Department of Physiology, University College of Medicine \& Dentistry, Pakistan
}

Submission: February 21, 2017; Published: March 20, 2017

*Corresponding author: Samina Malik, Department of Physiology, UCMD, PhD Physiology scholar, IMBB, UOL, MBBS (NMC), M. Phil (UHS), Alternate healer (Medicina Alternativa, Alma Ata), University College of Medicine \& Dentistry, Pakistan, Email: drsemymalik58@gmail.com

\begin{abstract}
Background: Pineal that is regarded as seat of soul \& intuition is said to be activated by 3rd eye meditation which involves alpha to theta rhythm on EEG. Its connections are studied with Hypothalamo-pituitary-Adrenal axis and Retina. Its role in reproduction, biological rhythms, psychosomatic illness and hence cancer is under study. Violet colored aura has been observed around pineal by Kirlian photography camera. Pineal has abundance of Phosphorus and also oxygen through blood supply, further favored by deep inhalation during meditation. Focused thinking or meditation involves ATP and breakdown of phosphate bonds in pineal may be involved. A biochemical parameter of pineal function is melatonin hormone. Hypothesis: Pineal can be stimulated by psychic / behavioral stimuli like violet light \& 3rd eye meditation to produce its psycho-neuro endocrine effects along with circadian rhythm regulation \& such stimuli may treat breast cancer. Material \& Methods: A Quasi-Experimental Interventional pilot study on 30 cancer patients aged 20-40 years with equal gender distribution, diagnosed at stage 1 before the onset of chemotherapy to be divided equally in intervention groups A, B and C. Electroencephalography will be monitored and brain scan conducted before \& after intervention. Melatonin levels will be measured by ELISA before \& after. In group A, $\mathrm{B}$ and $\mathrm{C}$ respectively, there will be intervention with recitation, 3rd eye meditation and violet light therapy (wave length 1000 to $2000 \mathrm{~Hz}$ ). Immediately Expected Results: More luminous aura of pineal during activation, slow rhythm on EEG during meditation, increase in melatonin level on stimulation, increasing peaks on Neuro MRI due to breakdown of high energy phosphate bonds and presence of functional dye at pineal level. Late Expected Results: With weekly treatment by the violet light / other stimuli, prognosis of breast cancer may improve over a period of one year. Benefits \& future prospects: This may serve to treat Breast and other cancers, depression, mania, bipolar, epilepsy, schizophrenia, fears \& phobias, sleep disorders, menstrual and hormonal Irregularities.
\end{abstract}

Keywords: Pineal gland; Psychoneuroendocrine transducer; Light therapy; Behavioral stimuli; Cancer

\section{Introduction}

Pineal which for Descartes was the seat of soul has remained a focus of study as a third-eye and a seat of intuitive knowledge. It has its Anatomical and physiological connections with Hypothalamo-pituitary-Adrenal axis and also with Retina [1]. Its role is studied in relation with reproduction and biological rhythms but its role in meditation is not highlighted. Although third-eye meditation by focusing at the mid eyebrow level is the commonest type of meditation believed to be responsible for achieving oneness of body, mind and soul. Pineal which is accepted as a neuro-endocrine transducer has turned out to be of interest for biological psychiatry and behavioral physiology and will soon be proved as a psycho-neuro-endocrine transducer. When the mind is healthy [2-8], body is healthy and certain diseases are attributed to mind over body effects. Involvement of Pineal in psycho-somatic diseases is being unveiled. Decreased function of pineal or removal of pineal has recently been associated with schizophrenia, depression, sleep disorders and Menstrual irregularities. So, it has more to do as a psycho somatic transducer, standing as a mediator on the boundary between soma and psyche.

The aura around pineal gland was studied by Dr. Valorie Hunt in his research at UCLA in 1988. It was reflected in violet colour, i.e, frequency range 1000 to $2000 \mathrm{~Hz}[9,10]$. It can be visualized by Kirlian photography that can produce colourful images of electromagnetic fields or Chakras of our body, with violet colour reflection at the level of pineal chakra or 6th chakra 
at mid-eyebrow level. Its suggests that pineal may be activated by different variables like violet coloured light with frequency (1000 to $2000 \mathrm{~Hz}$ ) or by third-eye meditation which will activate the pineal chakra as well and produce brighter image of violet colour on Kirlian photography.

Also a researcher in Philadelphia discovered that during meditation the frontal lobes are activated by concentration and spiritual or psychic feedback while parietal lobes are quiescent during such activities as parietal lobes are associated with 3 dimensional knowledge only [11-15]. Pineal gland is said to be associated with the fourth dimension and intuitive thinking, so it is quite likely that pineal is stimulated before facilitation of left prefrontal lobe during meditation. It is further studied that during meditation a person is in an altered state of consciousness and E.E.G pattern shows slow waves and alpha to theta variations when the person goes deeper gradually with more and more withdrawal from the surrounding environment and all other thoughts and external stimuli are totally rejected for more than 15 minutes or simply a person is in meditation phase [16], when EEG shows alpha rhythm. Focused thinking or meditation involves energy so ATP is required and breakdown of phosphate bonds in pineal must be involved. Since phosphate bonds are high energy twisted bonds produced by combination of phosphorus with oxygen, there should be a rich source of raw material for that energy rich compound with the pineal glands which is purposely privileged by rich blood supply as well. There are 2 important observations. Firstly, during meditation a person is breathing quietly through nose and inhaling oxygen more deeply than in normal state of consciousness. Secondly, it is established that pineal is the richest source of phosphorus in our body [17-24].

Thus it can be said that pineal produces its own energy for its important neuro-endocrine function once activated by psychic / behavioral stimuli. It can be shown by Neuro-MRI that gradually increasing peaks of breaking phosphate bonds can be seen on the scans with more and more activation of pineal gland. NASA America has established in a research on an American Jew who did not understand the Arabic Language of Holy Quran and suffered from an un-healing depression [25], who got cured by listening to the recitation at an appropriate frequency matched by the qirat of Surah Rehman by Qari Basit. It resulted in production of healing vibrations leading to the feelings of gratitude for Almighty that helped him cry out and get over with his depression and unveiled to him the translation of those verses without linguistic understanding. We hypothesize that Pineal can be stimulated by psychic / behavioral stimuli like violet light and 3rd eye meditation to produce its psycho-neuro endocrine effects along with circadian rhythm regulation and such stimuli may treat breast cancer [26].

\section{Material and Methods}

A cross-sectional case-control pilot study will be designed recruiting 30 controls aged 20-40 years with equal gender distribution and no history of breast cancer or any other cancer, depression, schizophrenia, epilepsy, sleep disorders and menstrual abnormalities related to circadian rhythm. A total of 30 breast cancer cases at stage 1 before the onset of chemotherapy will be recruited in intervention groups A, B and $C$ [27]. In all the 3 groups, there will be monitoring of EEG and brain scan before and after intervention and melatonin levels will be measured by ELISA to check the activity of pineal gland. In group $\mathrm{A}, \mathrm{B}$ and $\mathrm{C}$ respectively, there will be intervention with recitation, 3rd eye meditation and violet light therapy (wave length 1000 to $2000 \mathrm{~Hz}$ ) [28,29].

\section{Expected Results}

The following immediate results will be obtained:

Neuro MRI may reveal increasing peaks due to breakdown of high nergy phosphate bonds, more luminous violet light emission on Kirlian photography, slow EEG rhythm from alpha to theta and increased Melatonin levels after exposure to intervention. Longitudinal study over one year will be carried out to see the effect on prognosis of breast cancer after photo-therapy which is expected to improve (Table 1).

Table 1: Immediately expected results.

\begin{tabular}{|c|c|c|}
\hline $\begin{array}{c}\text { Aura by Kirlian } \\
\text { photography }\end{array}$ & Before Activation & After Activation \\
\hline EEG & Fast Rhythm (Beta) & $\begin{array}{c}\text { More luminous, more } \\
\text { violet light emission }\end{array}$ \\
\hline Melatonin & Baseline Levels & Increase Levels \\
to Theta)
\end{tabular}

\section{Late expected results}

With weekly treatment by the violet light, prognosis of breast cancer may improve over a period of one year.

\section{Benefits}

Non invasive treatment of so many pineal related disorders can be provided to patients with less hope and more risk from allopathic treatment.

This research can be a breakthrough in the life of the patients of
a. Breast cancer or any other cancer.
b. Depression, Mania, Biploar.
c. Epilepsy.
d. Schizophrenia. 
e. Fears and Phobias

f. Sleep Disorders

g. Menstrual Irregularities

h. Hormonal Irregularities specially related to reproduction.

i. Also intuitive thinking can be achieved in normal subjets.

j. It will open the door of further research in the latest field of psycho-Neuro-Endocrinology.

k. It will promote the newly regarded study of alternative medicine on scientific footings.

l. It will promote spirituality in practitioners of all religions and help them is their eternal journey to discovery of self-noor from Noor and back to Noor.

\section{References}

1. Bundzen PV, Korotkov KG, Unestahl LE (2002) Altered states of consciousness: review of experimental data obtained with a multiple techniques approach. J Altern Complement Med 8(2): 153-165.

2. Beck R (1986) Mood modification with ELF magnetic fields: A preliminary exploration. Archaeus 4: 48.

3. Bevk M, Kononenko, I, Zrimek T (2000) Relation between energetic diagnoses and GDV images. In: Proceedings of New Science of Consciousness Conference, pp. 54-58.

4. Boyers DG, Tiller WA (1973) Corona discharge photography. J Appl Physics 44: 3102-3112.

5. Bundzen P, Gavrilova E, Isakov V, Unestahl LE (1998) Stress limiting and immunomodulating effect of mental training. J Pathophysiol 5(1): 148

6. Bundzen P, Leisner P, Malinin A, Unestahl LE (1996) Mental relaxation: Neuro-dynamic markers and psycho physiological mechanisms. Current Research in Sports Sciences 91-101.

7. Bundzen P, Press Saad E (1984) Respuestas evocados de latencia media: mecanismos de generation y possible signifacado diagnostic. II Congreso de Ciencias Biologicas, pp. 220.

8. Charednechkenko UN (1997) Consciousness with the extended spacetime perception. J Parapsychol Psychophysics 2(24): 14-31.

9. Dobson P, O'Keffe E (2000) Investigations into stress and its management using the gas discharge visualization technique. Int J Altern Complement Med 3:12-17.

10. Ferguson PH (1975) The psychobiology of transcendental meditation. A review. J Altern States Consc 1: 15

11. Gowan J (1978) Altered states of consciousness. J Altern States Consc 4(2): 141-156.
12. Grof S, Bannett H (1992) The Holotropic Mind. San Francisco: Pavior Publishing.

13. Kim A Jobst, Bruce D Curtis, Richard C Niemtzow, Paul Ong, Wayne B Jonas, et al. (2004) Science and Healing: From Bioelectromagnetics to the Medicine of Light. The Journal of Alternative and Complementary medicine 9(2): 181-182.

14. Howell CJ (1999) The therapeutic effect of t'ai chi in the healing process of HIV. Int J Altern Complement Med 4: 16-20.

15. Illuchina V, Zabolotskich I (1993) Energy - deficient states of a healthy and diseased person. St. Petersburg, Russia: Nauka 192.

16. Koekina OI (1997) The brain activity transformation into the state of virtual consciousness. J Parapsychol Psychophysics 2(24): 41-47.

17. Korotkov K (1998) Aura and Consciousness: New Stage of Scientific Understanding. St. Petersburg, Russia: St. Petersburg Division of Russian Ministry of Culture, State Publishing Unit "Kultura” 301.

18. Korotkov K, Korotkin D (2001) On concentration dependence of gas discharge around drops of non-organic electrolytes (sic). J Appl Physics 9: 4732-4736.

19. Mandel P (1986) Energy Emission Analysis: New Application of Kirlian Photography for Holistic Medicine. Synthesis Publishing Co, Sulzbach, Taunus.

20. Oschman JL (2000) Energy Medicine. The Scientific Basis Edinburgh, London, and Churchill Living stone, New York, USA.

21. Pavlova LP, Romanenko AF (1988) System Approach to the Psycho physiological Study of the Brain. Saint-Petersburg, Nauka, Russia.

22. Spivak DL (1986) Linguistics of Altered States of Consciousness. SaintPtersburg, Russia: Nauka.

23. Syldona M, Rein G (1999) The use of DC dlectrodermal potential measurements and healer's felt sense to assess the energetic nature of qi. J Altern Complement med 5(4): 329-347.

24. Terner F, Poppel E (1995) Beauty and the Brain. Moscow: Nauka 74-96.

25. Tiller WA (1997) Science and Human Transformation: Subtle Energies, Internationality and Consciousness. Pavior Publishing, Lafayette CA, USA.

26. Unestahl LE, Bundzen P (1996) Integrated mental training - neuro biochemical mechanisms and psycho-physical consequences. J Hypnos 23(3): 148-156.

27. Volkov IP (1996) Human Body - Psychics: Synthesis of Scientific, Philosophic, and Religious Knowledge. Russia State University Publishing, St. Petersburg, Russia, pp. 186.

28. Wright PA (1995) The interconnectivity of mind, brain and behavior in altered state of consciousness: Focus on shamanism. Altern Ther Health Med 11(3): 50-56

29. Yoshida T, Ohmoto S, Kanamura S (1991) Proceedings of the $11^{\text {th }}$ International Conference on Noise in Physical Systems and $1 / \mathrm{f}$ Fluctuations. pp. 719-722. 


\section{Your next submission with Juniper Publishers} will reach you the below assets

- Quality Editorial service

- Swift Peer Review

- Reprints availability

- E-prints Service

- Manuscript Podcast for convenient understanding

- Global attainment for your research

- Manuscript accessibility in different formats (Pdf, E-pub, Full Text, Audio)

- Unceasing customer service

Track the below URL for one-step submission https://juniperpublishers.com/online-submission.php 